TITLE:

\title{
Effects of alkyl chain length on properties of N-alkyl-N- methylpyrrolidinium fluorohydrogenate ionic liquid crystals
}

\section{$\operatorname{AUTHOR}(\mathrm{S})$ :}

Xu, Fei; Matsubara, Shohei; Matsumoto, Kazuhiko; Hagiwara, Rika

\section{CITATION:}

$\mathrm{Xu}$, Fei ... [et al]. Effects of alkyl chain length on properties of $\mathrm{N}$-alkyl-N-

methylpyrrolidinium fluorohydrogenate ionic liquid crystals. Journal of Fluorine

Chemistry 2012, 135: 344-349

ISSUE DATE:

2012-03

URL:

http://hdl.handle.net/2433/154578

\section{RIGHT:}

(c) 2012 Elsevier B.V.; This is not the published version. Please cite only the published version.; この論文は出版社版でありません。引用の際に は出版社版をご確認ご利用ください。 
Effects of alkyl chain length on properties of $\mathrm{N}$-alkyl- $\mathrm{N}$-methylpyrrolidinium

\section{fluorohydrogenate ionic liquid crystals}

Fei Xu, Shohei Matsubara, Kazuhiko Matsumoto*, Rika Hagiwara

Graduate School of Energy Science, Kyoto University, Sakyo-ku, Kyoto 606-8501, Japan,

*E-mail: k-matsumoto@energy.kyoto-u.ac.jp

Tel: $+81-75-753-5822$

Fax: $+81-75-753-5906$

Key words: Ionic liquid, Liquid crystal, Pyrrolidinium, Mesophase, Conductivity 


\section{Abstract}

A series of $N$-alkyl- $N$-methylpyrrolidinium fluorohydrogenate salts $\left(\mathrm{C}_{x} \mathrm{MPyr}(\mathrm{FH}){ }_{2} \mathrm{~F}, x=10,12,14\right.$,

16, and 18) have been characterized by infrared spectroscopy, thermal analysis, polarized optical microscopy, X-ray diffraction, and anisotropic ionic conductivity measurements. Liquid crystalline mesophase with a smectic A interdigitated bilayer structure is observed for the salt with $x \geq 14$, showing a fan-like or focal conic texture. Temperature range of the mesophase increases with increase in alkyl chain length (from $26.7{ }^{\circ} \mathrm{C}$ for $\mathrm{C}_{14} \mathrm{MPyr}(\mathrm{FH})_{2} \mathrm{~F}$ to $90.7{ }^{\circ} \mathrm{C}$ for $\mathrm{C}_{18} \mathrm{MPyr}(\mathrm{FH})_{2} \mathrm{~F}$ ). The layer spacing in the smectic structure monotonously increases with increasing alkyl chain length and decreases with increasing temperature. The liquid crystalline mesophase of $\mathrm{C}_{14} \mathrm{MPyr}(\mathrm{FH})_{2} \mathrm{~F}$ exhibits anisotropy in ionic conductivity and the ionic conductivity parallel to the smectic layer is roughly ten times larger than that perpendicular to the smectic layer. 


\section{Introduction}

Ionic liquid crystals (ILCs) are composed of ionic species and have anisotropic structural organizations [1-2], which make them attractive as one-dimensional [3-5] or two-dimensional [6-8] ion-conductive materials to move a specific ion. Ionic liquids are widely studied as functional materials because of their unique characteristics such as wide liquid temperature range, negligible vapor pressure, and nonflammability [9]. Because of the widespread use of imidazolium-based ionic liquids with low melting point and low viscosity, imidazolium-based ILCs are frequently studied [10-13]. For example, 1-alkyl-3-methylimidazolium cations with long alkyl chains were combined with various anions such as chloride $\left(\mathrm{Cl}^{-}\right)$[10], bromide $\left(\mathrm{Br}^{-}\right)$[11], tetrachlorometallate $\left(\mathrm{MCl}_{4}^{-}, \mathrm{M}=\mathrm{Co}\right.$ and $\left.\mathrm{Ni}\right)$ [10], hexafluorophosphate $\left(\mathrm{PF}_{6}^{-}\right)$[12], tetrafluoroborate $\left(\mathrm{BF}_{4}^{-}\right)$[13], and trifluoromethanesulfonate $\left(\mathrm{OSO}_{2} \mathrm{CF}_{3}^{-}\right)$[11]. The temperature range of mesophase observed for these salts increases with increasing alkyl chain length, although the alkyl chain length with which liquid crystalline mesophase appears depends on the anionic species combined.

Fluorohydrogenate ionic liquids are attractive materials because of their low melting points, low viscosities, and high ionic conductivities $\left(100 \mathrm{mS} \mathrm{cm}^{-1}\right.$ for 1-ethyl-3-methylimidazolium fluorohydrogenate, $\left.\operatorname{EMIm}(\mathrm{FH})_{2.3} \mathrm{~F}\right)$ [14]. Such materials are potential electrolytes in various electrochemical devices such as electrochemical capacitors [15] and fuel cells [16-17]. In our previous study, we synthesized and characterized a series of 1-alkyl-3-methylimidazolium 
fluorohydrogenate $\left(\mathrm{C}_{x} \mathrm{MIm}(\mathrm{FH})_{2} \mathrm{~F}\right)$ ILCs [18]. These ILCs show a smectic A interdigitated bilayer structure in liquid crystalline mesophase, and the temperature range of the mesophase increases with increasing alkyl chain length. They show high anisotropy in ionic conductivity and the ionic conductivity parallel to the smectic layer $\left(\sigma_{/ /}\right)$is higher than that perpendicular to the smectic layer $\left(\sigma_{\perp}\right)$. The dominant charge carrier in these ionically conductive layers is thought to be $(\mathrm{FH})_{2} \mathrm{~F}^{-}$, since the cation is much larger than the anion and linked to the adjacent cation by van der Waals interactions $[6-8,18]$. Degree of the anisotropy increases with increasing alkyl chain length, since the insulating alkyl-chain layers are developed more by introducing longer alkyl chains.

Ionic liquids based on pyrrolidinium cations attract attention because of their relatively high electrochemical stability compared with imidazolium cations [19]. However, pyrrolidinium-based ILCs are seldom studied in previous reports [20-21]. Different from ILCs based on $\mathrm{C}_{x} \mathrm{MIm}^{+}$cation, which show only smectic A phase in all the cases, smectic T phase with tetragonal symmetry was also observed for ILCs based on $\mathrm{C}_{x} \mathrm{MPyr}^{+}$cation, and the type of the mesophase depends on both the anion and the carbon number $x$ [20-21]. In this study, a series of $N$-alkyl- $N$-methylpyrrolidinium fluorohydrogenate salts $\left(\mathrm{C}_{x} \mathrm{MPyr}(\mathrm{FH})_{2} \mathrm{~F}, x=10,12,14,16\right.$, and 18) were synthesized. Thermal, physical, and structural properties of the obtained fluorohydrogenate salts were studied by differential scanning calorimetry (DSC), polarized optical microscopy (POM), and X-ray diffraction (XRD). Anisotropy in ionic conductivity was also measured. 


\section{Results and discussion}

\subsection{Synthesis and general properties}

All the $\mathrm{C}_{x} \mathrm{MPyr}(\mathrm{FH})_{n} \mathrm{~F}(x=10,12,14,16$, and 18) salts were prepared by reaction of the corresponding chloride and excess anhydrous HF. While the $\mathrm{C}_{x} \mathrm{MPyr}^{+}$cation with a short alkyl chain $(x=2,4$, and 6$)$ gives the vacuum-stable HF composition $n$ of 2.3 [14-15,19,22-24], the present cations with relatively long alkyl chain $(x=10,12,14,16$, and 18) give $n$ equals to or less than 2.3. Similar behavior was observed for imidazolium salts $\left(\mathrm{C}_{x} \mathrm{MIm}^{+}\right.$with $x=8,10,12,14,16$, and 18). In order to investigate effects of alkyl chain length on properties of $\mathrm{C}_{x} \mathrm{MPyr}(\mathrm{FH})_{n} \mathrm{~F}$, the $n$ value was adjusted to 2.0 by either removing $\mathrm{HF}$ at elevated temperatures or mixing two fluorohydrogenate salts with $n$ values less than and greater than 2.0 (See Scheme 1 for the structures of $\mathrm{C}_{x} \mathrm{MPyr}^{+}$and $\left.(\mathrm{FH})_{2} \mathrm{~F}^{-}\right)$. All the resulting salts do not have a detectable HF dissociation pressure up to $45^{\circ} \mathrm{C}$. The $(\mathrm{FH})_{n} \mathrm{~F}^{-}$anions can be best identified by infrared (IR) spectroscopy [25]. At room temperature, the $\mathrm{C}_{10} \mathrm{MPyr}(\mathrm{FH})_{2} \mathrm{~F}$ salt is liquid, while the $\mathrm{C}_{x} \mathrm{MPyr}(\mathrm{FH})_{2} \mathrm{~F}(x=12,14,16$, and 18) salts are wax-like solids. Hygroscopicity and solubility into water are lower for the fluorohydrogenate salts with longer alkyl chain.

\subsection{Thermal Properties}

Thermogravimetric (TG) analysis suggested the decomposition temperature of $\mathrm{C}_{x} \mathrm{MPyr}(\mathrm{FH})_{2} \mathrm{~F}$ with long alkyl chain is about $200{ }^{\circ} \mathrm{C}$ (Fig. S2, Supporting Information), which is similar to the 
cases of $\operatorname{DMPyr}(\mathrm{FH})_{2} \mathrm{~F}$ and $\operatorname{EMPyr}(\mathrm{FH})_{2.3} \mathrm{~F}$ [19]. The decomposition temperatures of the $\mathrm{C}_{x} \mathrm{MPyr}(\mathrm{FH})_{2} \mathrm{~F}$ salts are slightly lower than those of the $\mathrm{C}_{x} \mathrm{MIm}(\mathrm{FH})_{2} \mathrm{~F}$ salts $\left(230{ }^{\circ} \mathrm{C}\right)[18]$, indicating the lower thermal stability of pyrrolidinium cations compared to imidazolium cations. Figure 1 and Table 1 show the DSC curves and the thermal parameters (transition temperatures, $\Delta H$, and $\Delta S$ ) obtained for $\mathrm{C}_{x} \mathrm{MPyr}(\mathrm{FH})_{2} \mathrm{~F}$ from the curves, respectively. Three endothermic peaks are observed for $\mathrm{C}_{x} \operatorname{MPyr}(\mathrm{FH})_{2} \mathrm{~F}(x=14,16$, and 18), which are ascribed to the solid-solid phase transition, melting (from crystal to liquid crystal), and clearing (from liquid crystal to isotropic liquid) with increasing temperature. The break of a three-dimensionally ordered crystal lattice on melting is reflected in the relatively large $\Delta H$ and $\Delta S$. The small $\Delta H$ and $\Delta S$ at clearing point, which increase with the increase in $x$, are mainly caused by the breakup of van der Waals interactions between the alkyl chains. Similar phenomena were also observed for other $\mathrm{C}_{x}$ MPyr-based ILCs [20] and $\mathrm{C}_{x} \mathrm{MIm}$-based ILCs [11-13]. For $\mathrm{C}_{10} \mathrm{MPyr}(\mathrm{FH})_{2} \mathrm{~F}$ and $\mathrm{C}_{12} \mathrm{MPyr}(\mathrm{FH})_{2} \mathrm{~F}$, only two endothermic peaks are observed. The peak at higher temperature corresponds to melting point, and the peak for clearing point is not observed even during the cooling process before crystallization, suggesting the tetradecyl or longer alkyl group is required for the $\mathrm{C}_{x} \mathrm{MPyr}^{+}$cation to form liquid crystalline mesophase. A solid-solid phase transition during the heating process is observed in all the cases. One of the possible reasons for this transition is the change in conformation of alkyl chain as was reported for the $\mathrm{C}_{x} \mathrm{MIm}^{+}$cations with long alkyl chain [26]. Another possible factor is rotation around the long alkyl chain since many pyrrolidinium salts exhibit solid-solid transitions due to the 
increase in rotational degrees of freedom $[20,27]$. The $\mathrm{C}_{10} \mathrm{MPyr}(\mathrm{FH})_{2} \mathrm{~F}$ salt exhibits an exceptionally large solid-solid transition peak and the entropy change at the solid-solid transition (about $27.18 \mathrm{~J}$ $\mathrm{mol}^{-1} \mathrm{~K}^{-1}$ at $-40.3{ }^{\circ} \mathrm{C}$ ) is almost the same as that at melting point (about $24.34 \mathrm{~J} \mathrm{~mol}^{-1} \mathrm{~K}^{-1}$ at $-11.6^{\circ} \mathrm{C}$ ), suggesting that the high-temperature solid phase has a highly disordered structure. Possibility of isotropic rotation is probably low in the present cases because of the rod-like shape of the cation, whereas rotation around the long axis is probable even in the crystalline phase.

Figure 2 shows melting and clearing points of $\mathrm{C}_{x} \mathrm{MPyr}(\mathrm{FH})_{2} \mathrm{~F}$ plotted as a function of carbon number $x$. Liquid crystalline mesophase is observed with $x \geq 14$. The melting point increases with increasing alkyl chain length, while the clearing point increases more sharply (from 80.4 to $162.7^{\circ} \mathrm{C}$ ) compared with the melting point (from 53.7 to $72.0^{\circ} \mathrm{C}$ ), leading to the wider temperature range of liquid crystalline mesophase for the cation with a longer alkyl chain $\left(\right.$ e.g. $26.7{ }^{\circ} \mathrm{C}$ for $\mathrm{C}_{14} \mathrm{MPyr}(\mathrm{FH})_{2} \mathrm{~F}$ and $90.7{ }^{\circ} \mathrm{C}$ for $\left.\mathrm{C}_{18} \mathrm{MPyr}(\mathrm{FH})_{2} \mathrm{~F}\right)$. This can be explained by the increase in van der Waals interactions between the alkyl chains and a similar trend was also observed for other $\mathrm{C}_{x} \mathrm{MPyr}$ [20] and $\mathrm{C}_{x} \mathrm{MIm}[10,12-13]$ salts because of their similar rod-like cation structures. Although $\mathrm{C}_{x} \mathrm{MIm}(\mathrm{FH})_{2} \mathrm{~F}$ gives a liquid crystalline mesophase with $x \geq 10, \mathrm{C}_{x} \mathrm{MPyr}(\mathrm{FH})_{2} \mathrm{~F}$ does with $x \geq 14$. Imidazolium ring has acidic ring protons at C2 position which can interact with anions and such an interaction facilitates formation of polar layers in a smectic phase and stabilizes the liquid crystalline mesophase. Pyrrolidinium cations do not have this interaction and requires a longer alkyl chain to form a liquid crystalline mesophase. 


\subsection{Structural properties}

Figure 3 shows a polarized optical microscopic (POM) texture of $\mathrm{C}_{14} \mathrm{MPyr}(\mathrm{FH})_{2} \mathrm{~F}$ typical for the $\mathrm{C}_{x} \operatorname{MPyr}(\mathrm{FH})_{2} \mathrm{~F}$ ILCs $(x=14,16$, and 18$)$, which is characterized as smooth fan-like or focal conic textures. Absence of smectic $\mathrm{C}$ mesophase is confirmed since broken fan-like texture, which is indicative of smectic $\mathrm{C}$ mesophase, was not observed in the liquid crystalline mesophase on cooling from isotropic phase to crystalline phase [28-29]. Based on the observation above, the liquid crystalline mesophase of $\mathrm{C}_{x} \mathrm{MPyr}(\mathrm{FH})_{2} \mathrm{~F}$ is assigned to smectic A mesophase $[1,10,12-13]$. Besides smectic A mesophase, smectic T mesophase was also observed for other $\mathrm{C}_{x} \mathrm{MPyr}$ ILCs [20]. This is in contrast to the $\mathrm{C}_{x}$ MIm ILCs which show only smectic A liquid crystalline mesophase [10-13].

Figures 4 and 5 show X-ray diffraction (XRD) patterns of $\mathrm{C}_{x} \mathrm{MPyr}(\mathrm{FH})_{2} \mathrm{~F}$ in the crystalline phase and liquid crystalline mesophase (isotropic phase for $x=10$ and 12), respectively. Sharp peaks are observed in the low $2 \theta$-angle region $\left(2^{\circ}<2 \theta<5^{\circ}\right)$ for $x=14,16$, and 18 , indicating formation of layered structures in both the phases. No sharp peak was found for $\mathrm{C}_{10} \mathrm{MPyr}(\mathrm{FH})_{2} \mathrm{~F}$ and $\mathrm{C}_{12} \mathrm{MPyr}(\mathrm{FH})_{2} \mathrm{~F}$ above melting point, which suggests the absence of liquid crystalline mesophase and agrees with the results of DSC. No additional peak was observed in the high $2 \theta$-angle region $\left(6^{\circ}<2 \theta<30^{\circ}\right)$ for $\mathrm{C}_{x} \mathrm{MPyr}(\mathrm{FH})_{2} \mathrm{~F}(x=14,16$, and 18), suggesting the loss of positional ordering within the smectic layer plane (Fig. 5), which fits the characteristics of smectic A mesophase. A highly ordered smectic $\mathrm{T}$ phase was also observed for $\mathrm{C}_{x} \mathrm{MPyrBr}(11 \leq x \leq 20), \mathrm{C}_{18} \mathrm{MPyrBF}_{4}$, and 
$\mathrm{C}_{18} \mathrm{MPyrPF}_{6}$, in which the cationic head groups and anions are ordered to form a tetragonal lattice

[20]. In the smectic $\mathrm{T}$ phase, the XRD pattern shows several peaks and the layer spacing is independent of temperature. This highly ordered phase can be observed for spherical or highly symmetrical anions $\mathrm{Br}^{-}, \mathrm{BF}_{4}^{-}$, and $\mathrm{PF}_{6}^{-}$, but not for linear anions of $\mathrm{SCN}^{-}$. Since $(\mathrm{FH})_{2} \mathrm{~F}^{-}$has a bent shape (Scheme 1), cationic head groups and anions do not seem to fit into a tetragonal lattice to form a smectic $\mathrm{T}$ phase.

Figure 6 shows layer spacings $(d)$ of $\mathrm{C}_{x} \mathrm{MPyr}(\mathrm{FH})_{2} \mathrm{~F}$ in the crystalline phase $(x=10,12,14,16$, and 18) and liquid crystalline mesophase $(x=14,16$, and 18) as a function of temperature (See Table S2 for the detailed values). In both the phases, increase in $x$ results in increase in $d$, due to their longer alkyl chains. In the liquid crystalline mesophase, the layer spacing $d$ satisfies the relation of $l<d<2 l$, where $l$ is the fully extended length of the cation, suggesting an interdigitated bilayer structure formed in the smectic A mesophase (smectic $\mathrm{A}_{2}$ ) which is also confirmed by the decrease of $d$ against temperature (see Fig. 7) [11,18]. It is likely that either alkyl chain of the cation is tilted with respect to the polar sheet or the alkyl chains interdigitate more deeply in the crystalline phase compared to the liquid crystalline mesophase [11-12], since smaller layer spacings compared to that of the liquid crystalline mesophase are observed [20-21]. Discontinuous gaps are also observed in the crystalline phase at the temperature where the endothermic peaks appear in DSC, which is ascribed to the solid-solid phase transition. Detailed examination of the XRD patterns (Figures S6-S8, Supporting Information) reveals that $\mathrm{C}_{x} \mathrm{MPyr}(\mathrm{FH})_{2} \mathrm{~F}(x=14,16$, and 18) have two 
different crystal structures below and above the solid-solid phase transition temperature (between 0 and $20{ }^{\circ} \mathrm{C}$ for $\mathrm{C}_{18} \mathrm{MPyr}(\mathrm{FH})_{2} \mathrm{~F}$, between -20 and $0{ }^{\circ} \mathrm{C}$ for $\mathrm{C}_{16} \mathrm{MPyr}(\mathrm{FH})_{2} \mathrm{~F}$, and between -40 and $-20{ }^{\circ} \mathrm{C}$ for $\left.\mathrm{C}_{14} \mathrm{MPyr}(\mathrm{FH})_{2} \mathrm{~F}\right)$. The XRD pattern of $\mathrm{C}_{12} \mathrm{MPyr}(\mathrm{FH})_{2} \mathrm{~F}$ at $-40{ }^{\circ} \mathrm{C}$ contains the peaks observed at $-20{ }^{\circ} \mathrm{C}$. (Figure S5, Supporting Information), indicating it is a mixture of two solid phases, and the solid-solid phase transition temperature is around $-40{ }^{\circ} \mathrm{C}$, which agrees well with the results of DSC. The $\mathrm{C}_{10} \mathrm{MPyr}(\mathrm{FH})_{2} \mathrm{~F}$ salt undergoes a solid-solid phase transition between $-40{ }^{\circ} \mathrm{C}$ and $-20{ }^{\circ} \mathrm{C}$, with a significant change in the XRD patterns, although the peak at $4.08^{\circ}$ still remain (Fig. S4). Upon heating from $-20{ }^{\circ} \mathrm{C}$ to $-15{ }^{\circ} \mathrm{C}$, the intensity of the peak at $4.08^{\circ}$ decreases ( $2 \theta$-angle also changes slightly) but the others increase. The peak at $3.91^{\circ}$ at $-15^{\circ} \mathrm{C}$ is not the residual peak of the low temperature phase but the new peak ascribed to the high temperature phase. Interestingly, the high temperature phase gives more peaks than those of the low temperature phase. This phenomenon suggests two possibilities; the high temperature phase has a lower symmetry than the lower temperature phase or two different high temperature phases appear at $-15^{\circ} \mathrm{C}$ due to polymorphism.

\subsection{Anisotropic ionic conductivity}

Conductivities parallel $\left(\sigma_{/ /}\right)$and perpendicular $\left(\sigma_{\perp}\right)$ to the smectic layer were measured for $\mathrm{C}_{x} \operatorname{MPyr}(\mathrm{FH})_{2} \mathrm{~F}(x=10,12$, and 14). The cell equipped with gold and ITO glass electrodes were used for this measurement [18]. Due to the decomposition of fluorohydrogenate salts to liberate HF 
to etch the glass substrate at elevated temperatures, the measurements of $\sigma_{/ /}$and $\sigma_{\perp}$ were limited up

to 55 and $65{ }^{\circ} \mathrm{C}$, respectively. Measurement of the conductivity for $\mathrm{C}_{16} \mathrm{MPyr}(\mathrm{FH})_{2} \mathrm{~F}$ and $\mathrm{C}_{18} \mathrm{MPyr}(\mathrm{FH})_{2} \mathrm{~F}$ was difficult due to their relatively high melting point $\left(64.4{ }^{\circ} \mathrm{C}\right.$ for $\mathrm{C}_{16} \mathrm{MPyr}(\mathrm{FH}){ }_{2} \mathrm{~F}$, and $72.0{ }^{\circ} \mathrm{C}$ for $\left.\mathrm{C}_{18} \mathrm{MPyr}(\mathrm{FH})_{2} \mathrm{~F}\right)$. Pseudo-isotropic textures were observed when the sample was placed in the cell with a pressure applied on the cover glass as in the case of $\mathrm{C}_{x} \mathrm{MIm}(\mathrm{FH})_{2} \mathrm{~F}$ ILCs. Rotation of the sample on the stage did not change the texture, indicating formation of a homeotropic alignment [18,29].

Figure 8 shows temperature dependence of $\sigma_{/ /}$and $\sigma_{\perp}$ for $\mathrm{C}_{x} \mathrm{MPyr}(\mathrm{FH})_{2} \mathrm{~F}(x=10,12$, and 14) (See Table S3 for the $\sigma_{/ /}$and $\sigma_{\perp}$ values at each temperature). The $\mathrm{C}_{10} \mathrm{MPyr}(\mathrm{FH})_{2} \mathrm{~F}$ and $\mathrm{C}_{12} \mathrm{MPyr}(\mathrm{FH})_{2} \mathrm{~F}$ salts do not exhibit a significant anisotropy in ionic conductivity, due to the absence of liquid crystalline mesophase. For $\mathrm{C}_{14} \mathrm{MPyr}(\mathrm{FH})_{2} \mathrm{~F}, \sigma_{/ /}$is about ten times higher than $\sigma_{\perp}$ in liquid crystalline mesophase, suggesting the high ion mobility in the ionic layer. The conductivity of ionic liquids based on $N$-alkyl- $N$-methylpyrrolidinium cation usually decreases with increasing alkyl chain length because of increase in viscosity [19], whereas $\sigma_{/ /}$for $\mathrm{C}_{14} \mathrm{MPyr}(\mathrm{FH})_{2} \mathrm{~F}$ salt shows a higher conductivity than $\mathrm{C}_{12} \mathrm{MPyr}(\mathrm{FH})_{2} \mathrm{~F}$ owing to formation of the well-ordered ion-conductive layers. The dominant charge carrier in these ion-conductive layers is considered to be $(\mathrm{FH})_{2} \mathrm{~F}^{-}$, since the cation is much larger than the anion and linked to the adjacent cation by van der Waals interactions $[18,30]$. Such a conduction mechanism implies application of the fluorohydrogenate ILC as electrolytes in some electrochemical systems where the fluorohydrogenate anion is involved with 
the electrode reactions.

\section{Conclusions}

Thermal, structural, and ion-conductive properties of $N$-alkyl- $N$-methylimidazolium fluorohydrogenate ILCs, $\mathrm{C}_{x} \mathrm{MPyr}(\mathrm{FH})_{2} \mathrm{~F}(x=10,12,14,16$, and 18), have been investigated. The ILCs show a smectic $\mathrm{A}_{2}$ mesophase and the temperature range of the mesophase increases with increasing alkyl chain length. The layer spacing of the interdigitated bilayer structures increases with increasing alkyl chain length both in the crystalline phase and liquid crystalline mesophase. Anisotropy was observed in ionic conductivity of $\mathrm{C}_{14} \mathrm{MPyr}(\mathrm{FH})_{2} \mathrm{~F}$ because of formation of the smectic layered structure.

\section{Experimental}

\subsection{General}

Volatile materials were handled in a vacuum line constructed of SUS316 stainless steel and PFA (tetrafluoroethylene-perfluoroalkylvinylether copolymer). Nonvolatile materials were handled under a dry $\mathrm{Ar}$ atmosphere in a glove box. The starting chlorides, $\mathrm{C}_{x} \mathrm{MPyrCl}(x=10,12,14,16$, and 18), were prepared by reactions of 1-methylpyrrolidine (Aldrich, $97 \%$ ) and equimolar quantities of the corresponding chloroalkanes (1-chlorodecane (TCI-EP), 1-chlorododecane (TCI-EP, $97 \%$ ), 1-chlorotetradecane (Aldrich, 98\%), 1-chlorohexadecane (Wako Chemicals, $95 \%$ ), 
1-chlorooctadecane (Wako Chemicals, $95 \%$ )) at temperatures ranging from 70 to $100{ }^{\circ} \mathrm{C}$ for several days. Purification of the chlorides was performed by dissolving the salts in acetonitrile (dehydrated, Wako Chemicals, $99.5 \%$ ) and then precipitating from the solution by adding ethyl acetate (dehydrated, Wako Chemicals, $99.5 \%$ ). Anhydrous HF (Daikin Industries) was dried over $\mathrm{K}_{2} \mathrm{NiF}_{6}$ prior to use.

\subsection{Synthesis of $C_{x} M P y r(F H)_{2} F$}

The starting chloride, $\mathrm{C}_{x} \mathrm{MPyrCl}$, was weighed in a PFA reactor under a dry Ar atmosphere and a large excess of anhydrous $\mathrm{HF}$ was distilled on that at $-196^{\circ} \mathrm{C}$. The mixture reacted on warming up to room temperature and the volatile gases were roughly eliminated by evacuation using a rotary pump. Elimination of the volatile gases and addition of fresh HF were repeated for effective elimination of chloride in the form of hydrogen chloride from the salt. Fluorohydrogenate salts $\mathrm{C}_{x} \mathrm{MPyr}(\mathrm{FH})_{n} \mathrm{~F}$ with the specific $\mathrm{HF}$ composition of 2.0 were prepared by removing $\mathrm{HF}$ at elevated temperatures or mixing two fluorohydrogenate salts with different $n$ values (less than and greater than 2.0). The HF composition of the obtained salts was confirmed by elemental analysis and titration using aqueous $0.1029 \mathrm{M} \mathrm{NaOH}$ (see Table $\mathrm{S} 1$ for the results of determination of the HF composition).

\subsection{Analytical methods}


Infra-red spectra of solid and liquid samples were obtained by FTS-165 (BIO-RAD Laboratories).

The samples were sandwiched between a pair of $\mathrm{AgCl}$ crystal windows in an airtight cell made of stainless steel. Thermogravimetric and DSC analyses were performed under a dry Ar gas flow using Shimadzu DTG-60H and Shimadzu DSC-60, respectively, at the scanning rate of $5{ }^{\circ} \mathrm{C} \mathrm{min}^{-1}$. The sample was placed in a $\mathrm{Ni}$ open cell for TG and in a sealed cell made of stainless steel for DSC. Polarized optical microscopy was carried out using a VHX digital microscope (Keyence) under cross-polarized light at $\times 100$ magnification. The sample was placed in a transparent cell made of sapphire and covered with a piece of glass substrate. The temperature was controlled by TS1500 hot stage unit (Japan High Tech). X-ray diffraction was performed using a Rigaku Ultima IV diffractometer $(\mathrm{CuK} \alpha, \lambda=1.542 \AA)$. The output power was set as $40 \mathrm{kV}-40 \mathrm{~mA}$. The data were recorded in the $2 \theta$ range of $2-30^{\circ}$ (scanning rate of $1^{\circ}$ per minute) with a step of $0.01^{\circ}$. The heating and cooling rate of $5{ }^{\circ} \mathrm{C} \min ^{-1}$ was used. The ionic conductivity was measured by impedance technique using PARSTAT 2273 electrochemical measurement system (Princeton Applied Research). Ionic conductivities, $\sigma_{/ /}$and $\sigma_{\perp}$, were measured according to the previously reported method [3-8]. A pair of comb-shaped gold electrodes were used to measure $\sigma_{/ /}$. Gold (about $0.8 \mu \mathrm{m}$ in thickness) was deposited on a borosilicate glass substrate in a comb shape after treatment of indium tin oxide (ITO) deposition (about $0.1 \mu \mathrm{m}$ ) in the pattern to reinforce the contact on the glass. The sample was placed in the comb-shaped region covered with a piece of glass substrate to help the alignment. A pair of ITO (indium tin oxide) glass electrodes was used to measure $\sigma_{\perp}$ [3-8]. The 
sample was sandwiched with two ITO glass electrodes and fixed with a PTFE spacer $(50 \mu \mathrm{m}$ in thickness). The cell constants of these cells were calibrated with a $\mathrm{KCl}$ aqueous solution $(0.747 \mathrm{~g}$ $\left.\mathrm{kg}^{-1}\right), \mathrm{EMImBF}_{4}\left(\right.$ Kanto Kagaku) and $\mathrm{BMImPF}_{6}$ (Kanto Kagaku). These conductivity measurement cells were placed in an airtight cell to avoid the effects of water. The cell was held at each temperature more than one hour except for the $\sigma_{/ /}$measurement of $\mathrm{C}_{14} \mathrm{MPyr}(\mathrm{FH})_{2} \mathrm{~F}$ at 50 and $55{ }^{\circ} \mathrm{C}$ after holding the temperature for 30 minutes to obtain a steady resistance, and the measurement was repeated several times to confirm reproducibility of the data. No etching of the glass surface was observed after the measurement.

\section{Acknowledgements}

This work was financially supported by the Grant-in-Aid for Scientific Research of Japan Society for the Promotion of Science, \# 20246140.

\section{Appendix A. Supplementary data}

Supplementary data associated with this article can be found, in the online version. 


\section{References}

[1] K. Binnemans, Chem. Rev. 105 (2005) 4148-4204.

[2] T. Kato, Science 295 (2002) 2414-2418.

[3] M. Yoshio, T. Kagata, K. Hoshino, T. Mukai, H. Ohno, T. Kato, J. Am. Chem. Soc. 128 (2006) 5570-5577.

[4] M. Yoshio, T. Mukai, H. Ohno, T. Kato, J. Am. Chem. Soc. 126 (2004) 994-995.

[5] H. Shimura, M. Yoshio, K. Hoshino, T. Mukai, H. Ohno, T. Kato, J. Am. Chem. Soc. 130 (2008) 1759-1765.

[6] M. Yoshio, T. Mukai, K. Kanie, M. Yoshizawa, H. Ohno, T. Kato, Adv. Mater. 14 (2002) $351-354$.

[7] T. Mukai, M. Yoshio, T. Kato, M. Yoshizawa, H. Ohno, Chem. Commun. (2005) 1333-1335.

[8] K. Kishimoto, T. Suzawa, T. Yokota, T. Mukai, H. Ohno, T. Kato, J. Am. Chem. Soc. 127 (2005) 15618-15623.

[9] T. Welton, Chem. Rev. 99 (1999) 2071-2083.

[10]C. J. Bowlas, D. W. Bruce, K. R. Seddon, Chem. Commun. (1996) 1625-1626.

[11]A. E. Bradley, C. Hardacre, J. D. Holbrey, S. Johnston, S. E. J. McMath, M. Nieuwenhuyzen, Chem. Mater. 14 (2002) 629-635.

[12]C. M. Gordon, J. D. Holbrey, A. R. Kennedy, K. R. Seddon, J. Mater. Chem. 8 (1998) $2627-2636$. 
[13]J. D. Holbrey, K, R. Seddon, J. Chem. Soc. Dalton Trans. (1999) 2133-2139.

[14]R. Hagiwara, K. Matsumoto, Y. Nakamori, T. Tsuda, Y. Ito, H. Matsumoto, K. Momota, J. Electrochem. Soc. 150 (2003) D195-D199.

[15]A. Senda, K. Matsumoto, T. Nohira, R. Hagiwara, J. Power Sources 195 (2010) 4414-4417.

[16]R. Hagiwara, T. Nohira, K. Matsumoto, Y. Tamba, Electrochem. Solid-State Lett. 8 (2005) A231-A233.

[17]J. Lee, T. Nohira, R. Hagiwara, J. Power Sources 171 (2007) 535-539.

[18]F. Xu, K. Matsumoto, R. Hagiwara, Chem. Eur. J. 16 (2010) 12970-12976.

[19]K. Matsumoto, R. Hagiwara, Y. Ito, Electrochem. Solid-State Lett. 7 (2004) E41-E44.

[20]K. Goossens, K. Lava, P. Nockemann, K. Van Hecke, L. Van Meervelt, K. Driesen, C. Görller-Walrand, K. Binnemans, T. Cardinaels, Chem. Eur. J. 15 (2009) 656-674.

[21] A. Getsis, A. Mudring, Z. Anorg. Allg. Chem. (2009) 2214-2221.

[22] R. Hagiwara, T. Hirashige, T. Tsuda, Y. Ito, J. Fluorine Chem. 99 (1999) 1-3.

[23] R. Hagiwara, T. Hirashige, T. Tsuda, Y. Ito, J. Electrochem. Soc. 149 (2002) D1-D6.

[24] Y. Saito, K. Hirai, K. Matsumoto, R. Hagiwara, Y. Miyazaki, J. Phys. Chem. B 109 (2005) 2942-2948.

[25] R. Hagiwara, Y. Nakamori, K. Matsumoto, Y. Ito, J. Phys. Chem. B 109 (2005) 5445-5449.

[26]J. De Roche, C. M. Gordon, C. T. Imrie, M. D. Ingram, A. R. Kennedy, F. Lo Celso, A. Triolo, Chem. Mater. 15 (2003) 3089-3097. 
[27]D. R. MacFarlane, P. Meakin, J. Sun, N. Amini, M. Forsyth, J. Phys. Chem. B 103 (1999) 4164-4170.

[28]K. Goossens, K. Lava, P. Nockemann, K. Van Hecke, L. Van Meervelt, P. Pattison, K. Binnemans, T. Cardinaels, Langmuir 25 (2009) 5881-5897.

[29]I. Dierking, Textures of Liquid Crystals, WILEY-VCH, Weinhelm, (2003).

[30]N. Yamanaka, R. Kawano, W. Kubo, T. Kitamura, Y. Wada, M. Watanabe, S. Yanagida, Chem. Commun. (2005) 740-742. 
Table 1 Summary of DSC analysis for $\mathrm{C}_{x} \mathrm{MPyr}(\mathrm{FH})_{2} \mathrm{~F}\left(x=10,12,14,16\right.$, and 18) ${ }^{a}$

\begin{tabular}{|c|c|c|c|c|}
\hline$x$ & Transition & Temperature $/{ }^{\circ} \mathrm{C}$ & $\Delta H / \mathrm{kJ} \mathrm{mol}^{-1}$ & $\Delta S / \mathrm{J} \mathrm{mol}^{-1} \mathrm{~K}^{-1}$ \\
\hline 10 & Cryst-Iso & -11.6 & 6.36 & 24.34 \\
\hline 12 & Cryst-Iso & 32.2 & 9.62 & 31.54 \\
\hline \multirow[t]{2}{*}{14} & Cryst-SmA 2 & 53.7 & 13.17 & 41.94 \\
\hline & $\mathrm{SmA}_{2}-$ Iso & 80.4 & 0.31 & 0.88 \\
\hline \multirow[t]{2}{*}{16} & Cryst- $-\mathrm{SmA}_{2}$ & 64.4 & 18.51 & 54.87 \\
\hline & $\mathrm{SmA}_{2}-$ Iso & 125.9 & 0.45 & 1.13 \\
\hline \multirow[t]{2}{*}{18} & Cryst- $\mathrm{SmA}_{2}$ & 72.0 & 20.84 & 60.42 \\
\hline & $\mathrm{SmA}_{2}$-Iso & 162.7 & 0.73 & 1.67 \\
\hline
\end{tabular}




\section{Figure captions}

Fig. 1 Differential scanning calorimetric curves (heating process) for $\mathrm{C}_{x} \mathrm{MPyr}(\mathrm{FH})_{2} \mathrm{~F}(x=10,12$, 14,16 , and 18).

Fig. 2 Melting points ( $\square$ ) and clearing points $(\bullet)$ observed in the DSC thermogram (heating) of $\mathrm{C}_{x} \operatorname{MPyr}(\mathrm{FH})_{2} \mathrm{~F}(x=10,12,14,16$, and 18).

Fig. 3 Polarized optical microscopic texture of $\mathrm{C}_{14} \mathrm{MPyr}(\mathrm{FH})_{2} \mathrm{~F}$ at $70{ }^{\circ} \mathrm{C}$.

Fig. 4 X-ray diffraction patterns for $\mathrm{C}_{x} \mathrm{MPyr}(\mathrm{FH})_{2} \mathrm{~F}(x=10,12,14,16$, and 18) in the crystalline phase $\left(-40^{\circ} \mathrm{C}\right)$.

Fig. 5 X-ray diffraction patterns for $\mathrm{C}_{x} \mathrm{MPyr}(\mathrm{FH})_{2} \mathrm{~F}(x=10$ and 12$)$ in the isotropic phase $\left(-10{ }^{\circ} \mathrm{C}\right.$ for $x=10$ and $32{ }^{\circ} \mathrm{C}$ for $\left.x=12\right)$, and $\mathrm{C}_{x} \mathrm{MPyr}(\mathrm{FH})_{2} \mathrm{~F}(x=14,16$, and 18) in the liquid crystalline mesophase $\left(80^{\circ} \mathrm{C}\right)$.

Fig. 6 Layer spacings of $\mathrm{C}_{x} \mathrm{MPyr}(\mathrm{FH})_{2} \mathrm{~F}$ in the crystalline phase and liquid crystalline mesophase at different temperatures. The symbols $\mathrm{C}$ and LC after the number of carbon in the alkyl chain denote crystal and liquid crystal, respectively.

Fig. 7 Schematic drawing of the smectic $\mathrm{A}_{2}$ structure.

Fig. 8 Temperature dependence of $\sigma_{/ /}$and $\sigma_{\perp}$ for $\mathrm{C}_{x} \mathrm{MPyr}(\mathrm{FH})_{2} \mathrm{~F}(x=10,12$, and 14).

Scheme 1 Structures of (a) $\mathrm{C}_{x} \mathrm{MPyr}^{+}$and (b) $(\mathrm{FH})_{2} \mathrm{~F}^{-}$. 
Fig. 1

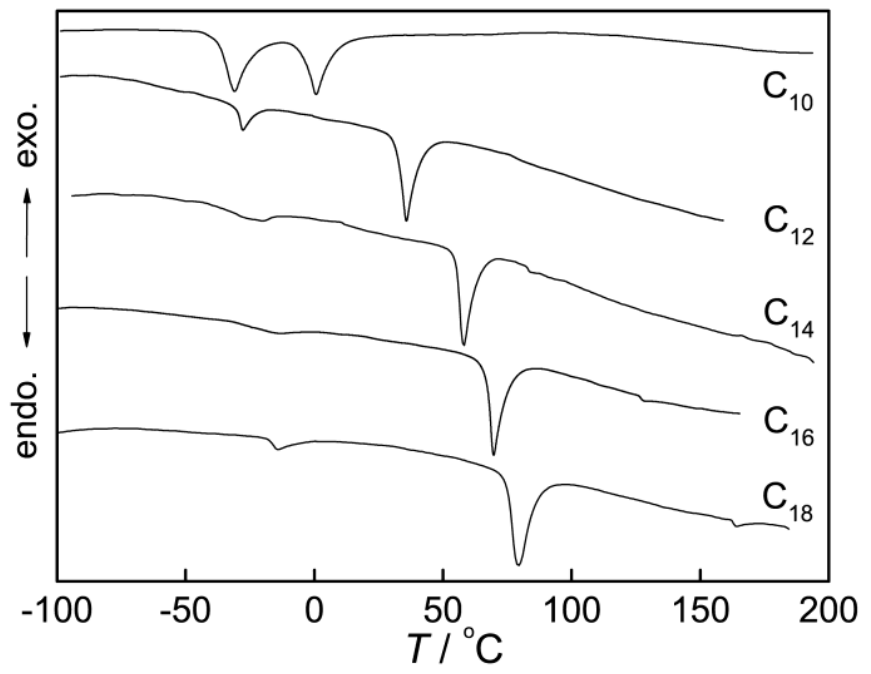


Fig. 2

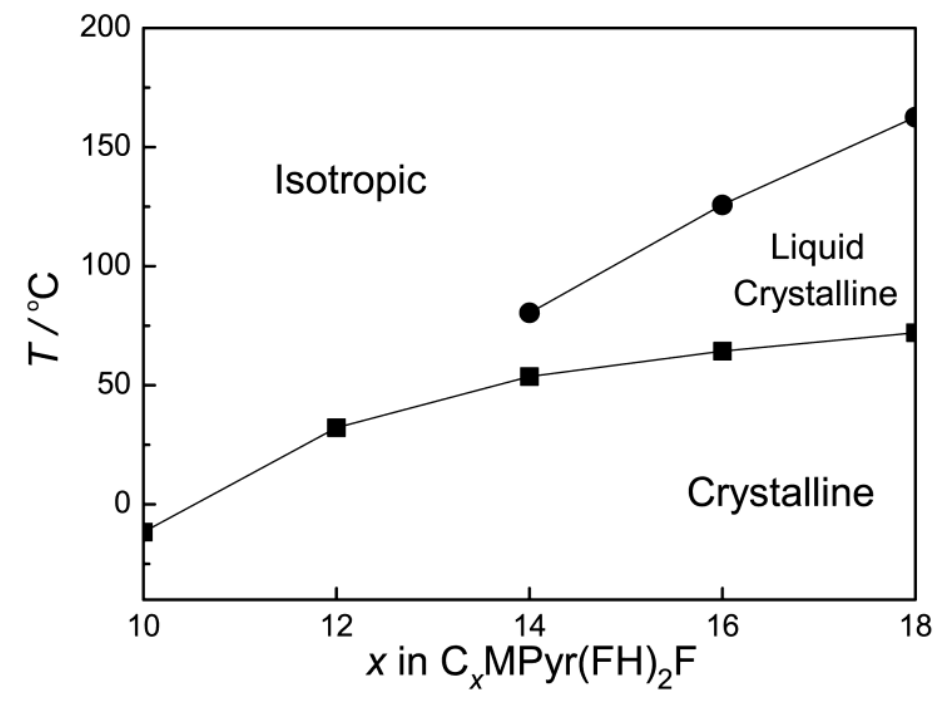


Fig. 3

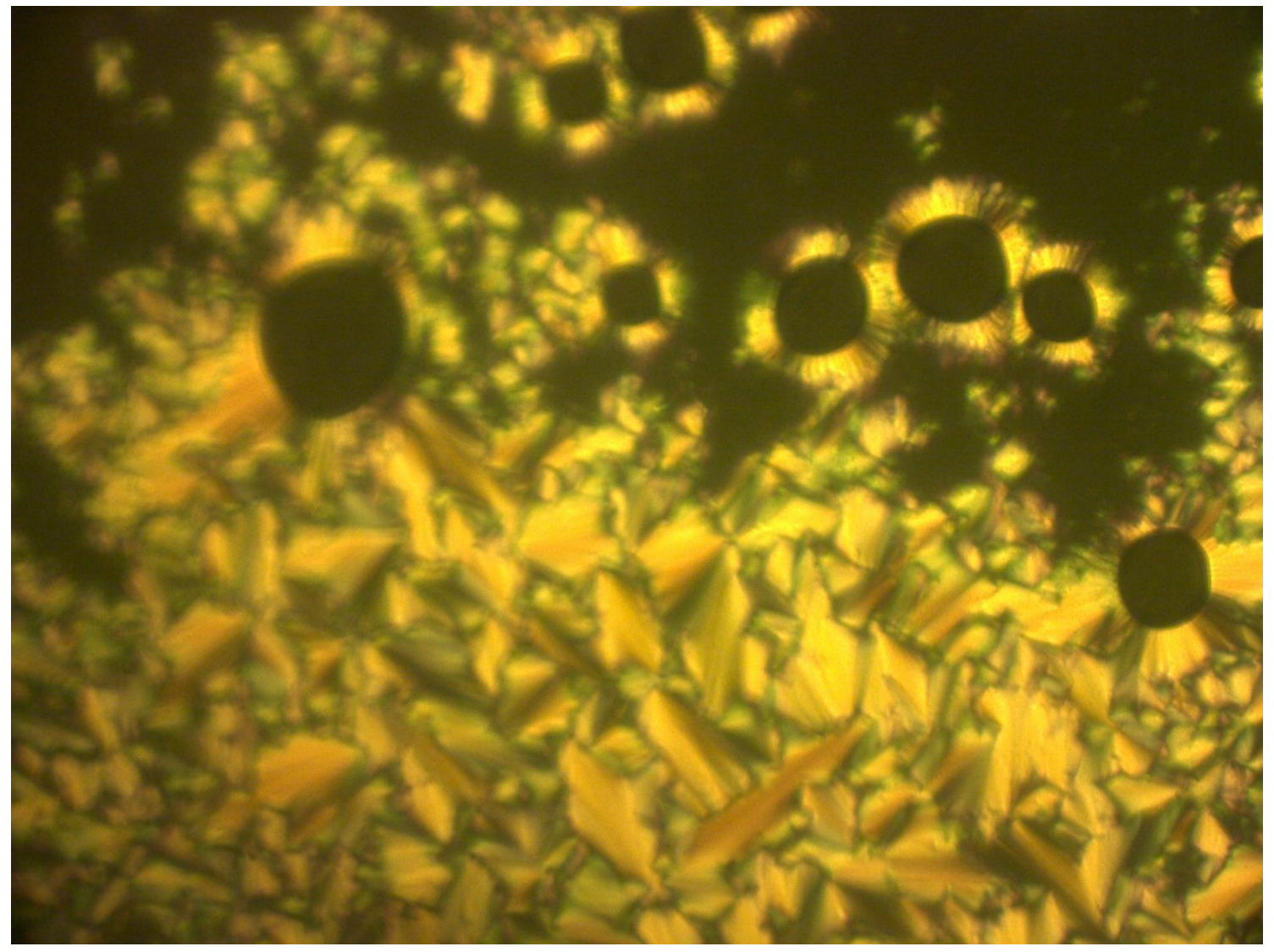


Fig. 4

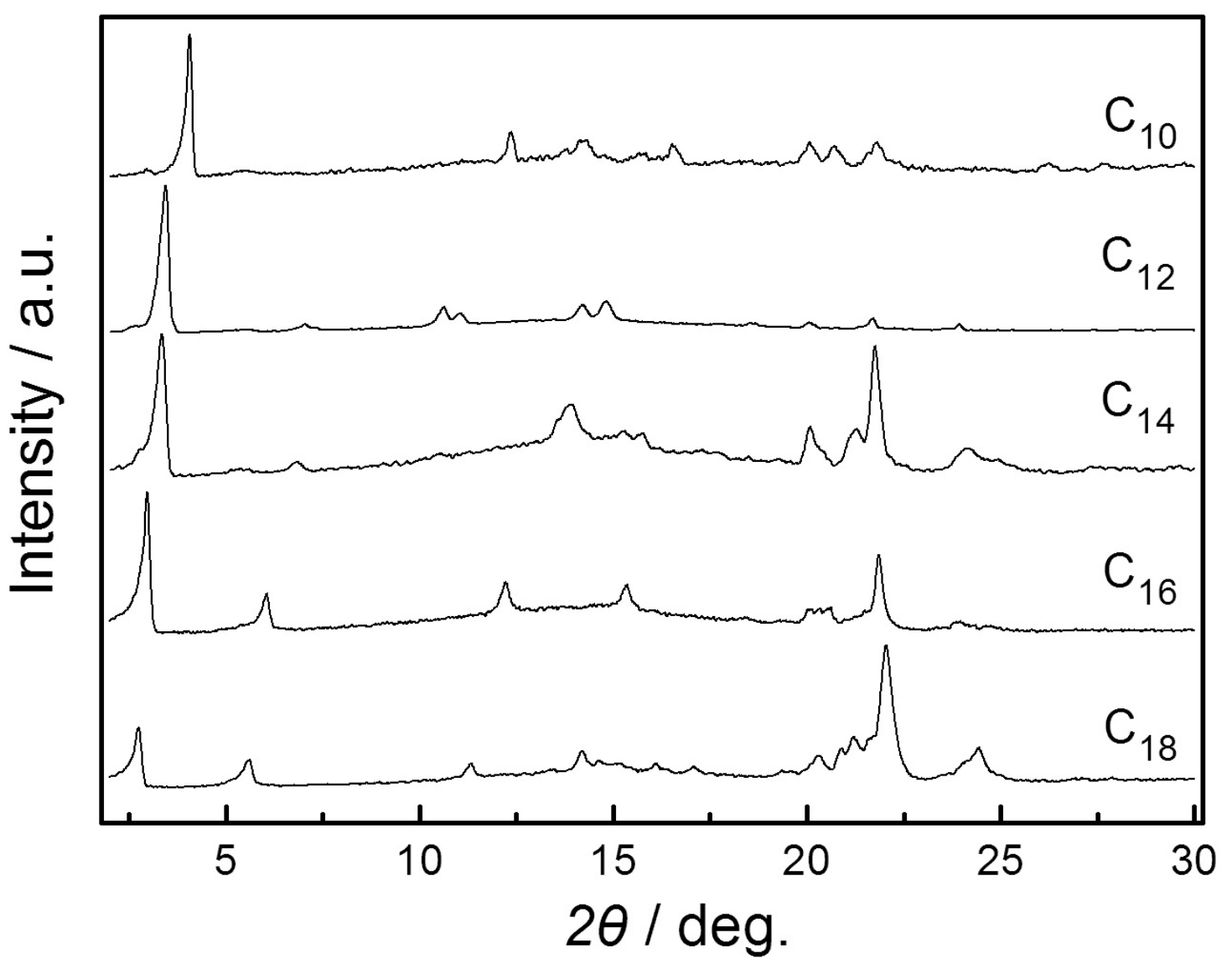


Fig. 5

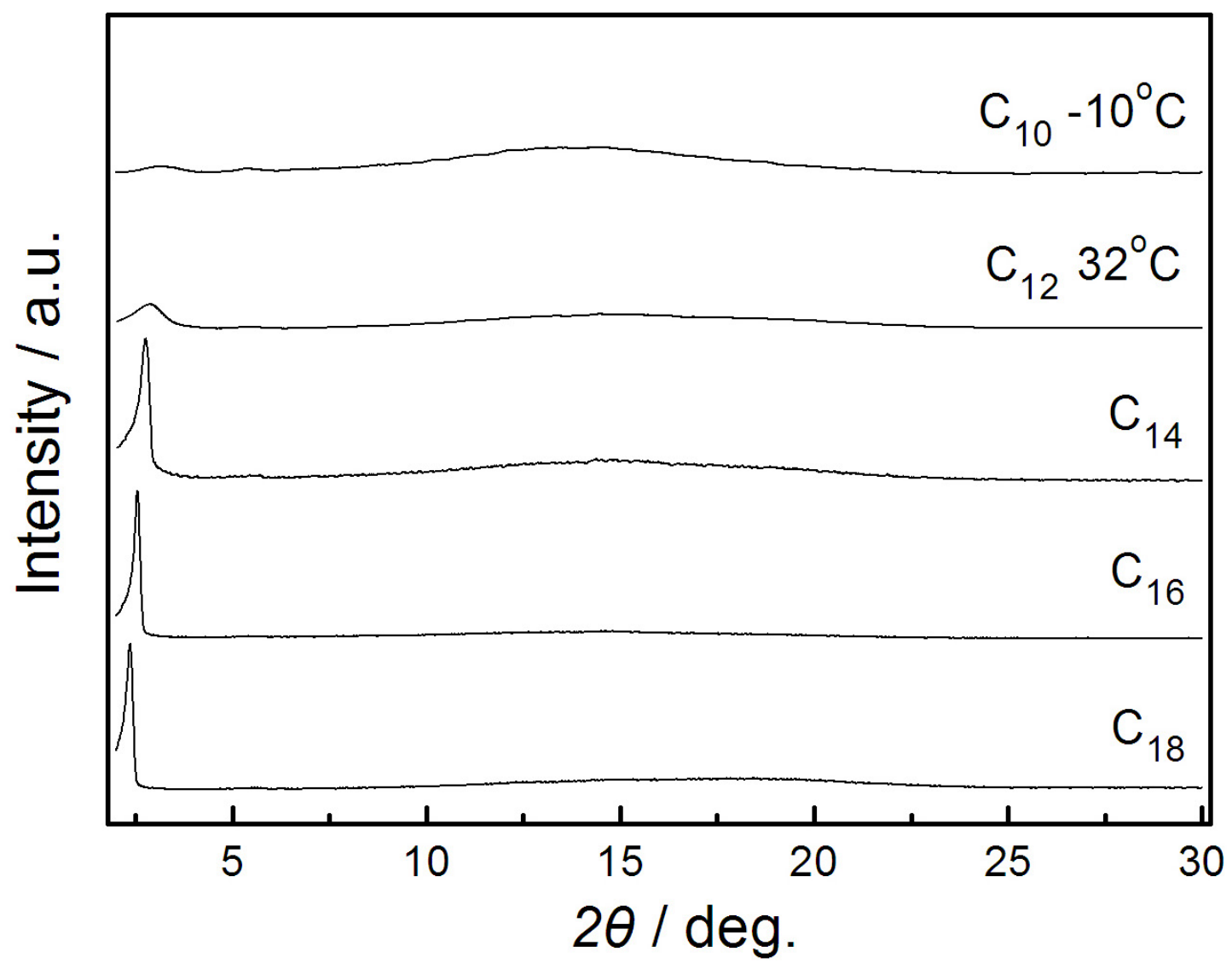


Fig. 6

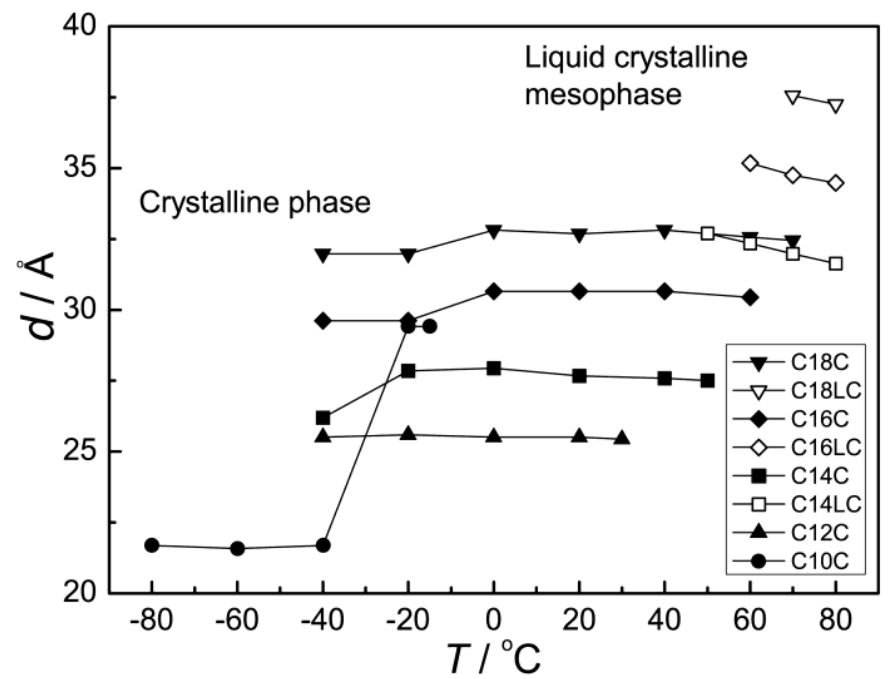


Fig.7

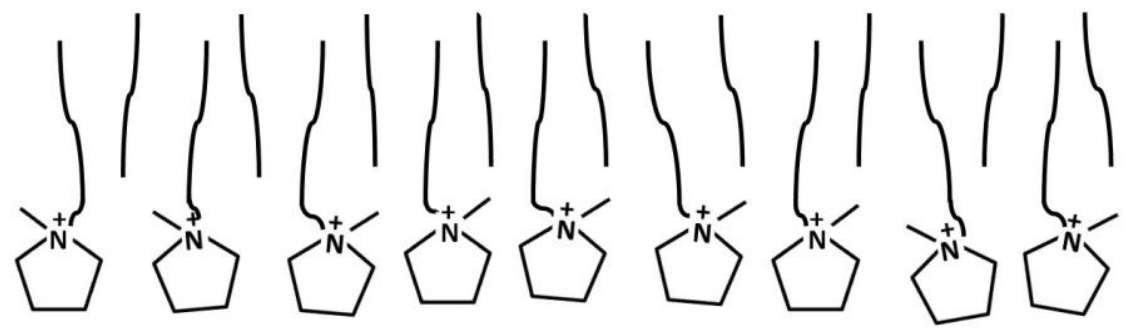

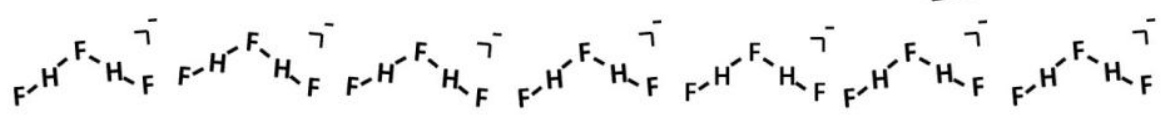

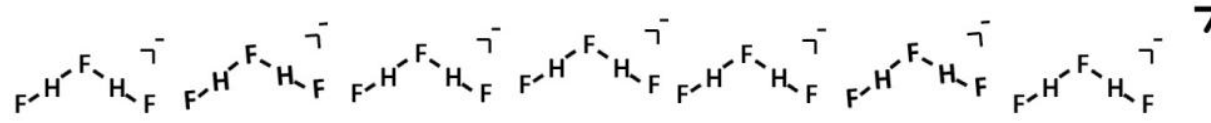

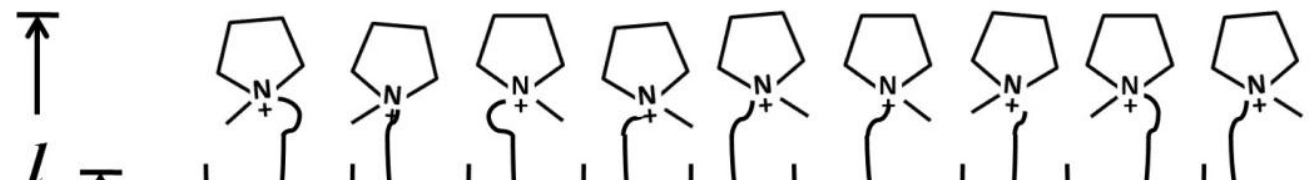

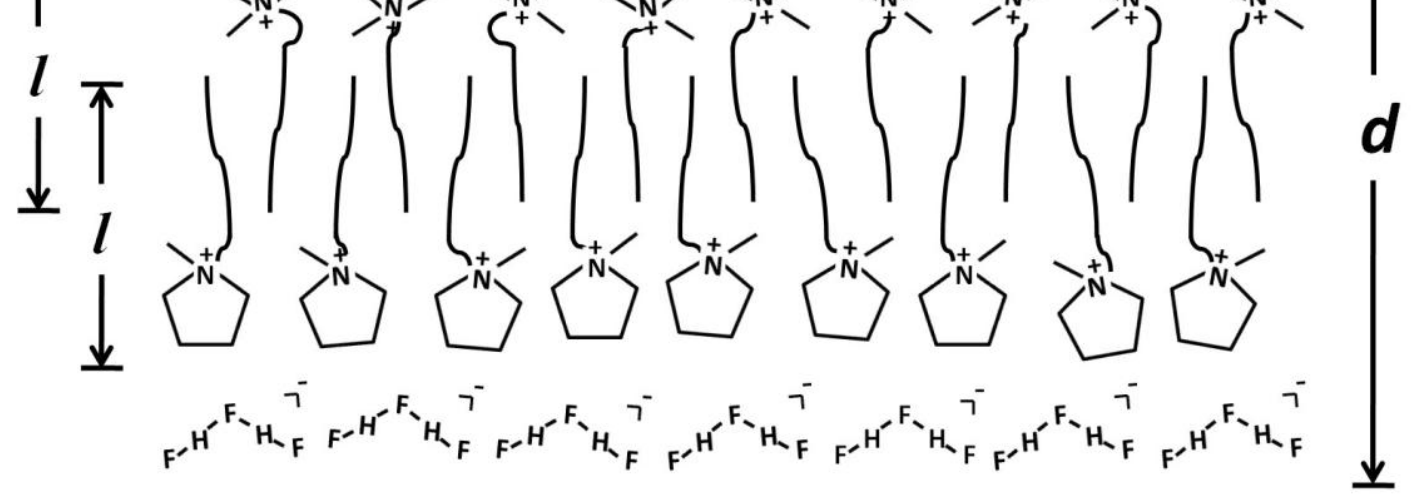

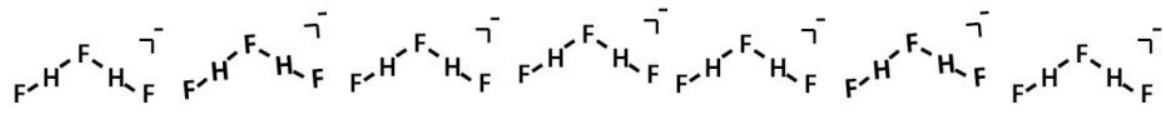

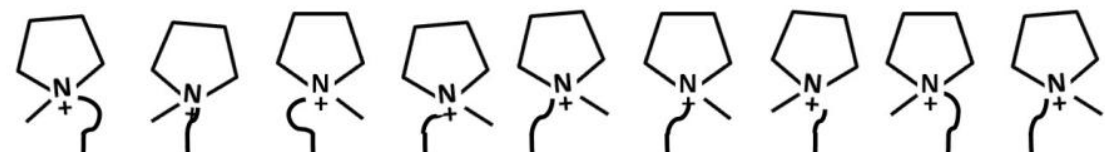

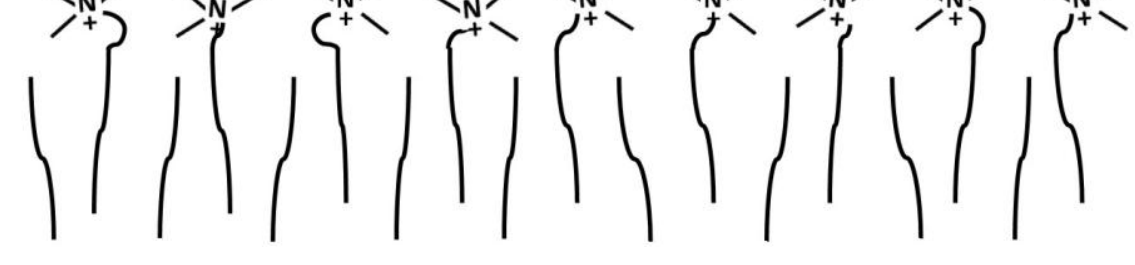


Fig. 8

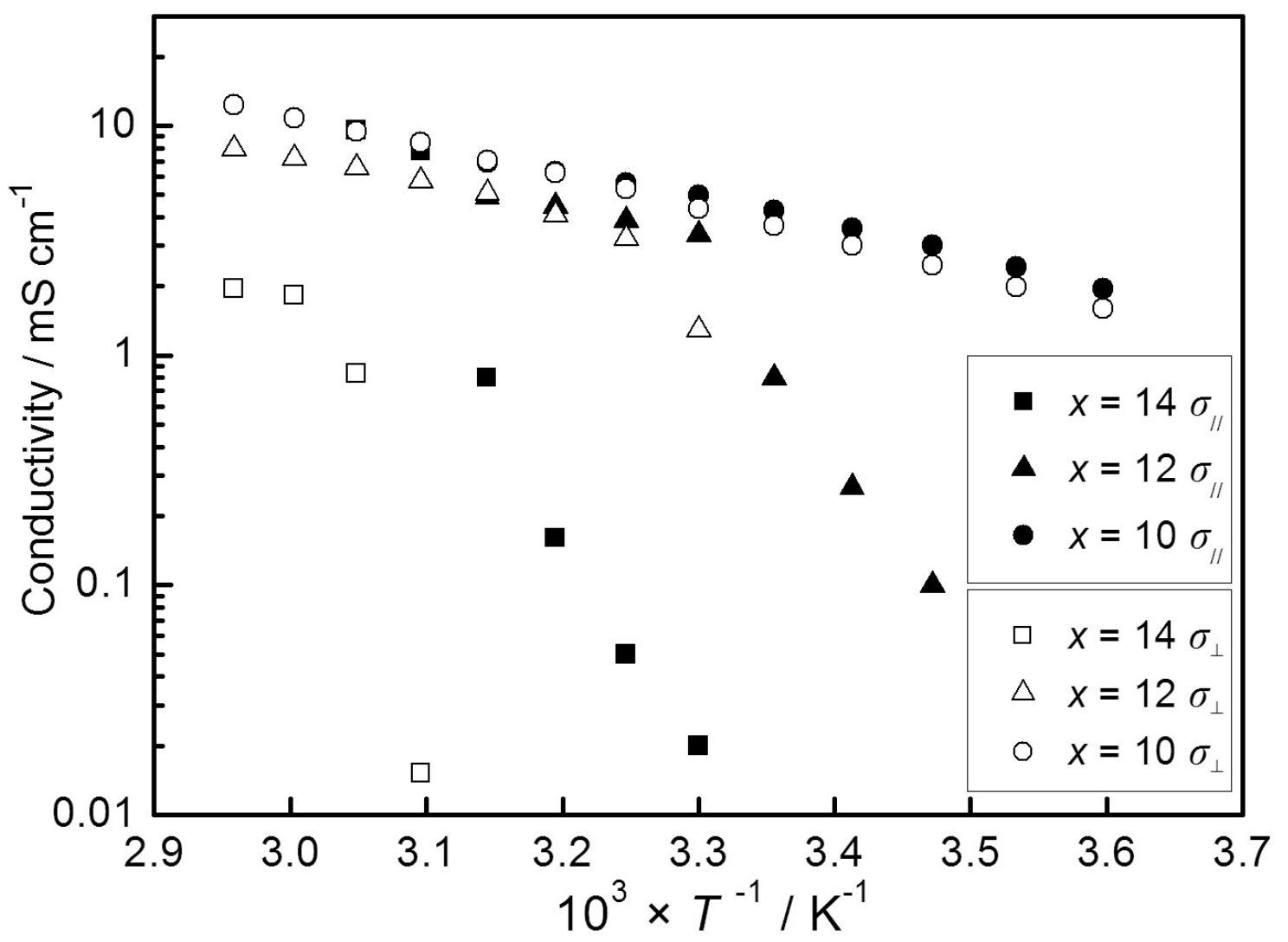


Scheme 1

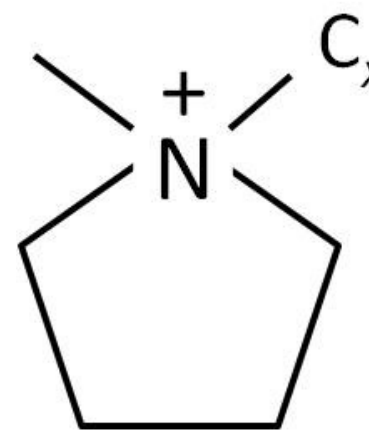

(a)

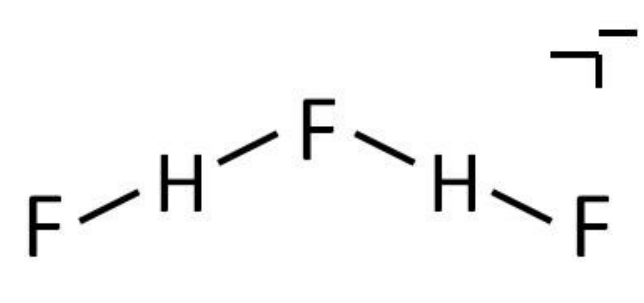

(b) 